\title{
Toplum 5.0’ın Mimarı Japonya'da Dezavantajlı Gruplar: Freeter, Hikikomori ve Parasaito Shinguru
}

\author{
Disadvantaged Groups in Japan, the Architect of Society 5.0: Freeter, \\ Hikikomori, and Parasaito Shinguru
}

Bilal Coşan' ${ }^{10}$

Öz

İnsanlık Toplum 1.0'dan Toplum 5.0'a kadar birçok olumlu gelişme yaşamasına rağmen tarihin her döneminde çeşitli sorunlarla da karşılaşmıştır. Yaşanan bu sorunlar neticesinde toplumun belli kesimleri her zaman dezavantajlı konumda olmuştur. Bu dezavantajlılık, sosyo-ekonomik birçok sebebe bağlı olarak ortaya çıkabilmektedir. Diğer yandan toplumlardaki belli başlı kültürel kodların varlığı da bu dezavantajılığın derinleşmesinde etkili olmaktadır. Bu bağlamda Toplum 5.0'ın mimarı olan Japonya gibi gelişmiş bir ülkede bile sosyal, ekonomik ve demografik sorunlara bağlı olarak dezavantajı gruplar ortaya çıkabilmektedir. Ayrıca bazı dezavantajlı grupların ortaya çıkmasında Japonya'nın sosyo-kültürel yapısı da etkili olmaktadır. Özellikle artan yaşlı nüfus, işgücü piyasasında yaşanan sorunlar, evlilik dinamiklerinin değişmesi, doğurganlık oranının azalması gibi sorunlar; ekonomik, demografik ve sosyal birçok problemin ortaya çıkmasına neden olmaktadır. Bu çalışma kapsamında Japonya'daki dezavantajlı gruplar; gençler, orta yaşılar ve yaşılır bağlamında değerlendirilecektir. Bu gruplar "freeter/furita", "hikikomori" ve "parasaito shinguru/parasite single" durumundaki bireylerdir. Çalışmada son olarak artan yaşlanan nüfusla beraber ortaya çıkan "kodokushi" sorunu değerlendirilecektir.

Anahtar Kelimeler

Hikikomori, Freeter, Parasaito Shinguru, Japonya, Dezavantajlı Gruplar

\begin{abstract}
Although humanity has experienced many positive developments from Society 1.0 to Society 5.0, it has also encountered various problems in every historical period. Due to these problems, certain segments of society have always been in a disadvantaged position. This disadvantageousness may be attributed to numerous socio-economic factors. Furthermore, some cultural codes in societies also contribute to deepening this disadvantageousness. In this context, even in a developed country such as Japan, which is the architect of
\end{abstract}

1 Sorumlu Yazar: Bilal Coşan (Doktora Öğrencisi), İstanbul Üniversitesi, Sosyal Bilimler Enstitüsü, Çalışma Ekonomisi ve Endüstri İlişkileri, İstanbul, Türkiye. E-posta: bilal.cosann@gmail.com ORCID: 0000-0002-8023-1129

Atıf: Cosan, B. (2021). Toplum 5.0'ın Mimarı Japonya'da Dezavantajlı Gruplar: Freeter, Hikikomori ve Parasaito Shinguru. Journal of Social Policy Conferences, 81. Advanced online publication. https://doi.org/10.26650/jspc.2021.81.913699 
Society 5.0, disadvantaged groups exist due to social, economic, and demographic problems. In addition, Japan's socio-cultural structure has also impacted the emergence of some disadvantaged groups. Especially the increasing elderly population, problems in the labor market, changing marital dynamics, and decreasing fertility rate have caused many economic, demographic, and social problems. Within the scope of this study focused on disadvantaged groups in Japan, we explored them in the context of young, middle-aged, and old people. These groups are freeter/ furita, hikikomori, and parasaito shinguru/parasite single. Finally, the kodoku-shi problem that emerges with the increasing aging population was investigated.

\section{Keywords}

Hikikomori, Freeter, Parasaito Shinguru, Japan, Disadvantaged Groups 


\section{Extended Summary}

Japan is a society with a long socio-economic and cultural history. Japan has set an example to the world in many areas, including business discipline, working culture, and family structure. Although Japan has developed considerably in every field since World War II, it encountered numerous problems after the 1980s. A series of changes, such as changing family structure, an increase in new types of jobs, and economic recessions, has caused many problems. Moreover, changes in Japanese culture were also effective in this process.

Japan, wanting to build a "people" centered society with Society 5.0, aims to enhance welfare. In this respect, based on the philosophy of Japan Society 5.0, it aims to distribute economic, technological, and social opportunities to all segments of society. In this context, social policies are implemented for disadvantaged groups in Japan, but some problems have become chronic and difficult to solve. For example, it is highly challenging to reverse an increase in the elderly population, average age of first marriage, and numbers of those who never married, as well as a decrease in fertility rates. In addition to the demographic and sociological problems mentioned, there are problems related to the labor market, such as the precarious working of many people with low wages due to the changing working dynamics. Therefore, some segments are unable to benefit from these welfare services in the process of Society 5.0. This is comparable with the process of the Industrial Revolution, which is described as "both the best and the worst of the times." Therefore, even in Japan, which is the architect of Society 5.0, due to some social, cultural, economic, and psychological problems, it does not seem possible to enhance the welfare of the whole society.

Within the scope of this study, after explaining the basic philosophy of Society 5.0, the socio-economic structure of Japan is explained in general. Subsequently, the emergence, limits, and problems of the concept of freeter, which directly refers to the position of young people in the labor market in Japan, are discussed. Although the concept is generally equated with "part-time work," there are many points where it is similar and different. Next, the concept of hikikomori, which is assumed to be unique to the Japanese culture in the beginning but has been observed in many societies over time, is emphasized. This concept, which can be defined as "social withdrawal" in short, is used to 
express the situation in which young people isolate themselves from society and their families for certain reasons (e.g., social, cultural, economic, and psychological). Next, the concept of kodoku-shi, which is defined as "death alone" as a result of an increase in aging individuals in Japan, is considered a social problem in Japan. Finally, individuals who are not married and known as "parasites" in Japan are also considered a social problem. These individuals are perceived as "parasites" because they do not marry, live with their families, and do not contribute to the family economy. Those in this group are named parasaito shinguru. As such, it is regarded as one of the groups held responsible by the Japanese government both for the declining birth rate and the aging population.

As a result, although the disadvantaged groups mentioned here are evaluated specifically for Japan, problems such as a decrease in fertility rate, the increasing average age for first marriage, an increase in the elderly population, and an increase in flexible and precarious working as a result of changing working dynamics are among the most fundamental problems of numerous developed and underdeveloped countries. 


\section{Toplum 5.0'in Mimarı Japonya'da Dezavantajlı Gruplar: Freeter, Hikikomori ve Parasaito Shinguru}

Toplum $5.0^{1}$ felsefesiyle "insan" merkezli bir toplum inşa etmek isteyen Japonya, refahı toplumun tüm kesimlerine ulaştırmayı amaçlamaktadır. Hâl böyle olunca Japonya, Toplum 5.0 anlayışıyla ekonomik, teknolojik ve sosyal imkânlardan toplumdaki tüm kesimlerin faydalanmasına yönelik sosyal politikalar geliştirmeyi hedeflemektedir. Ancak diğer yandan Japonya' da belli başlı sorunların yapısallaşması, refahın toplumun geneline yayılmasını zorlaştırmaktadır. $\mathrm{Bu}$ minvalde Japonya' da artan yaşı ıüfus, ilk evlilik yaşı ortalamasının artması, hiç evlenmeyenlerin oranındaki artış, doğurganlık oranlarının düşmesi vb. değişimler sorunların sosyolojik ve demografik yönüne işaret ederken, 1980'lerden sonra farklılaşmaya başlayan çalışma dinamikleri sebebiyle işgücü piyasasında birçok kişinin düşük ücretlerle, güvencesiz ve geçici işlerde çalışması da sorunun ekonomik boyutunu ortaya koymaktadır. Bu sorunlar neticesinde ortaya çıan dezavantajlı grupların Japon literatüründe birer sosyal sorun olarak görülmesi, bu dezavantajlı grupların kavramsallaştırılması ihtiyacını doğurmuştur.

Bu çalışma kapsamında Toplum 5.0'ın temel dinamikleri açıklandıktan sonra Japonya'nın sosyo-ekonomik yapısı hakkında genel bir izahat yapılacaktır. Daha sonra ilk olarak Japonya'da gençlerin işgücü piyasasındaki durumunu doğrudan ilgilendiren "freeter" kavramının gelişimi, kapsamı ve bununla ilgili sorunlar izah edilecektir. Zira kavram genelde "part-time çalışma" ile eş değer tutulsa da benzeştiği ve ayrıştığı noktalar bulunmaktadır. İkinci olarak "hikikomori" kavramı kapsamlıca açıklanacaktır. Kısaca "sosyal geri çekilme" olarak tanımlanabilecek bu kavram, gençlerin kendilerini belli sebeplerle (sosyal, kültürel, ekonomik, psikolojik vb.) toplumdan soyutladığı durumu ifade etmek için kullanılmaktadır. Üçüncü olarak Japonya' da yaşlanan bireylerin artışının bir sonucu olarak ortaya çıkan ve "yalnız ölüm" olarak ifade edilen "kodoku-shi" sorunu izah edilecektir. Son olarak Japonya'da "parasaito shinguru" olarak nitelendirilen ve evlenmeyen bireylerin durumu değerlendirilecektir. Bu bireylerin "parazit" olarak görülmelerinin sebebi, evlenmemeleri, aileleriyle beraber yaşamaları ve aile ekonomilerine katkı sağlamamalarıdır. Bu grup, Japon hükümeti nezdinde doğum oranlarının azalması ve nüfusun yaşlanmasından sorumlu tutulmaktadır.

1 Toplum 5.0 söyleminin Japonya'da çıkmasının arkasında, dinç ve zengin bir gelecek kurma arzusu, azalan nüfus enedişesi, aşırı yaşlanan toplum gibi sosyolojik nedenlerin olduğu bilinmelidir. Detaylı bilgi için bkz: (Dinler, 2020). 


\section{Toplum 5.0 Kavramı ve Sosyo-Ekonomik Göstergelerle Japonya}

2016 yılında Japon İş Federasyonu (Keidanren) tarafından kullanılan Toplum 5.0 kavramı (Koçak, 2020, s. 6), temel olarak geleceğin teknolojiyle inşa sürecini ifade etmek için kullanılmaktadır. Toplum 5.0'a kadar insanlığın Toplum 1.0'dan Toplum 4.0'a kadar sirasiyla avc1-toplayıc1 toplum, tarım toplumu, sanayi toplumu ve bilgi toplumu olmak üzere dört temel büyük değişim yaşadığ ifade edilmektedir. Toplum 5.0 ise süper akıllı toplum (supersmart society) olarak nitelendirilmektedir. Toplum 5.0, siber uzay ve fiziksel alan arasında gelişmiş yakınsama sağlayarak, büyük verilere ve robotlara dayalı yapay zekânın, insanların şimdiye kadar yaptığı işleri gerçekleştirmesine imkân sağlamaktadır. Toplum 5.0 felsefesi, yaş ve cinsiyet gözetmeksizin toplumun tüm kesimlerinin refahını artırmayı amaçlarken bu amacını hantal iş yapısından kurtulma ve zamanı etkin kullanma, evlere otonom taşıma hizmetleri sağlama, otonom ulaşım ve tarım araçları geliştirme, robot destekli bakım hizmetleri sağlama gibi her alanda birçok yenilikle gerçekleştirmeyi hedeflemektedir. Özetle, Japonya bu hedefleriyle tüm sosyal ve organizasyonel sistemleri optimize etmeyi amaçlamaktadır. (Japan Cabinet Office, 2021a).

Japonya günümüzde dünyanın 7 büyük ekonomisinden biri konumundadır. Reel Gayri Safi Yurtiçi Hasılası 2019 yılı verisine göre yaklaşık 5 trilyon ABD \$'1, kişi başına GSYİH 42.239 ABD \$'1 düzeyindedir. Nüfusu ise yaklaşık 126 milyondur. Güncel işsizlik oranlarına bakıldığında ise gelişmiş ülkelere kıyasla çok daha düşük düzeyde işsizlik oranına sahiptir. 2021 Nisan verisine göre \% 2,8 düzeyinde seyreden işsizlik oranları dünyadaki en düşük işsizlik oranları arasında gösterilebilir (Statistics Bureau of Japan, 2021a; WorldBank, 2021a; Worldbank, 2021b; OECD, 2021). Ancak pozitif verilerin ötesinde Japonya'da da birtakım sosyo-ekonomik sorunların varlığı göz ardı edilmemelidir. Zira zaman içerisinde yaşlanan nüfusuyla beraber farklı sorunlarla yüzleşen Japonya, ayrıca 1980'li y1llarda yaşanan ekonomik durgunluk neticesinde çeşitli problemlerle de karşı karşıya kalmıştır. Bu dönemde yaşanan ekonomik kriz; güvencesiz çalışma, part-time çalışma gibi yeni çalışma biçimlerinde artışların yaşanmasına neden olmuştur (Yılmaz ve Şahin, 2020, s. 31-32). Diğer yandan 1990'lı yıllarda Japon ekonomisinde yaşanan arz fazlalığı, ekonomik sorunların derinleşmesindeki en önemli etmenlerden biridir. Bu süreçte yaşlı nüfusun artmasına bağlı olarak iç talepte yaşanan azalma, arz fazlasına neden olmuş, bu duruma bağlı olarak şirketlerin uzun vadede kâr oranları düşmeye başlamıştır (Bulut, 2019, s. 21). 
COVID-19 pandemisi sürecinde kronik sorunları tekrardan nükseden Japonya ekonomisi, 1980'den beri yaşadığı en büyük ekonomik daralmalardan birini yaşamaktadır (Westelius, 2020, s. 1; Fernandes, 2020, s. 21-26).

Kolektif hareketin oldukça önemli olduğu bir toplum olan Japonya'da bireyin var oluşu bir nevi grupla mümkün olabilmektedir. Sürekli bir yarış halinde olan Japonlar; aile, okul, ilçe, il ve genelde ülke olmak üzere her ortamda bir grubu temsil etmektedir. Haliyle bu yarış aileden başlayarak özelden genele gelişerek devam etmektedir. Diğer yandan Japon kültürünün temelleri birbirine bağl1l1k üzerine kuruludur. Özellikle Japonya' da tarımın ağırlıkta olduğu dönemde sosyal alan içerisinde bu bağlılık ve birlikteliği görmek mümkündür. (Öz ve Vural, 2005, s. 105; Özşen, 2011, s. 69). Yaşam boyu istihdam, terfi ve ücretlendirmede hassasiyet, aile yapısı ve sosyal değerlerin önemi ve buna bağlı olarak örgütsel bağlılık gibi konular Japon iş ahlakının şekillenmesinde büyük öneme sahiptir (Sığr1, 2006, s. 30-40). Ancak günümüzde post endüstriyel toplumlarda yaşanan sosyo-ekonomik değişimler ve diğer yandan artan bireyselcilik Japonya'da da etkisini göstermektedir. Özellikle 19. yüzyılın son çeyreğinde (Meiji Dönemi) başlayan modernleşme hareketleri ve İkinci Dünya Savaşı'ndan sonra ekonomik ve sosyo-kültürel anlamda yaşanan köklü değişimler, tarımdan kopuş ve makineleşmenin artması bu değişim sürecinde etkili olmuştur (Özşen, 2020, 36-39). Bireysel rekabetin ön plana çıkıp bireyler arası dayanışmanın ikinci planda kalması, düşüncelerin ve ideallerin bireysel zeminde hayat bulması farklı sonuçları beraberinde getirmiştir. Bu açıdan bakıldığında Püriten ideallerden ve Protestan iş ahlakından kaynaklanan bireyselciliğin küreselleşme sürecinde Japonya üzerinde de ciddi etkilerinin olduğu söylenebilir. Yaşanan bu değişim neticesinde hem sosyal hem ekonomik hem psikolojik olarak Japonya' da da belli sorunların yaşanması kaçınılmaz olmuştur. (Uchida ve Norasakkunkit, 2015, s. 1-11). Özetle Japonya gibi ekonomik anlamda çok gelişmiş ve Toplum 5.0 anlayışıyla toplumun geneline refahı yaymayı amaç edinmiş bir ülkede dahi dezavantajlı grupları görmek mümkündür.

\section{Japonya'da Ekonomik Anlamda Dezavantajlı Olmak: "Freeter"}

Japonya'da 15 ile 34 yaş arasında lise ve üniversite mezunları, sabit ya da uzun vadeli kariyerler yerine gün geçtikçe daha fazla kısa vadeli ve yarı zamanlı işler tercih etmektedir. Bu kişilere Japonya'da "freeter" ya da "furitaa" 
denilmektedir. "Freeter" kavramı köken olarak İngilizce "free” (özgür) ile Almanca'da işçi anlamına gelen "arbeiter" kelimelerinin birleşiminden türetilmiştir. Bu kişiler ayrıca benzer kavramlar olan, "temps", "job hopers", "part-time workers", "freelancers" gibi kavramlarla da anılmaktadır (Rahman, 2007, s. 1-2). Freeterlerin zaman içerisinde yükselişi, genç neslin daha özgür olma arzusu ve tek bir şirkette tam zamanlı çalışma isteklerinin gün geçtikçe azalmasıyla yakından ilişkilidir. Daha esnek bir yaşam tarzını benimseyen freeterler, zaman zaman farklı iş türlerini deneyimleme arzusu içerisinde olabilmektedir (CrossCurrents, 2021). Diğer yandan 1990'lı yıllarda başlayan ekonomik durgunluk bu tür çalışma modelinin artmasını tetiklemiştir. Aynı şekilde okul-iş yaşamı arasındaki geçiş sürecinde yaşanan problemler de freeter sayısının artışında etkili olmuştur (Reiko, 2006, s. 1-2).

1980'lerde yaşam tarzını, özgürlüğü, bir şirkete bağlı olmamayı ve mevcut sisteme eleştiriyi ifade eden ve daha çok pozitif bir zeminde değerlendirilen freeter kavram1 ${ }^{3}$, 1990'larla beraber başlayan ekonomik depresyon ve buna bağlı olarak istihdam olanaklarının azalmasıyla negatif bağlamda değerlendirilmeye başlanmıştır. Zira bu süreçten sonra freeter olmak bir seçim olmaktan çıkıp, ekonomik konjonktürün bir sonucu olarak değerlendirilmiştir. Bu grup içerisindeki gençlerin bir kısmının belli hedeflerinin olmaması, Japon devleti açısından bir sorun olarak görülmektedir. Hal böyle olunca bu gruptakiler devlet açısından endişe verici insan kaynağı olarak değerlendirilmektedir (Kasuga, 2005, s. 1-2).

Freeter kavramının, NEET (Ne eğitimde ne istihdamda bulunanlar/Not in Employment, Education or Training), ve part time çalışanlarla kesiştikleri noktalar olduğu için kavramın ifade edilmesi ve sınırlarının çizilmesinde zaman zaman zorluklar yaşanabilmektedir. Genel olarak sınıflandırmaları Sağlık Çalışma ve Gönenç Bakanlığı 2003 Yılı Çalışma ve Ekonomi Yıllığı'nda;

- 15-34 yaş arasında mezun olmuş erkek ya da kadın (evli olmayan) kişiler

- Tam zamanlı çalışmayan kişiler

- İşsiz olup part-time işçi olarak çalışmak isteyen, öğrenci olmayan ve ev işleriyle (ev hanımı olmayan) meşgul olmayan kişiler

2 Japonca'da benzer olarak "Arubaito" (geçici iş̧̧i) kavramı kullanılmaktadır.

3 Kavram ilk defa 1987 yılında FromA adında bir iş ilanı dergisinde kullanılıışıtır (Filippini, 2012, s. 7). 
şeklinde yapılmaktadır (Rahman, 2007, s. 2). Ayrıca freeter olanlar 2000 yılında devletin yaptığı bir sınıflandırmada üç farklı kategoride değerlendirilmiştir. Bunlar (Pilz, Schmidt-Altmann ve Eswein, 2015, s. 86);

- Moratoryum freeterler (moratorium freeters)

- Alternatifi olmayan freeterler (no alternative freeters)

- Hayallerinin peşinde olan freeter (dream pursuing freeters)'lerdir.

Birinci grupta ifade edilen freeterler okul hayatlarındayken geleceğe dair plan yapmayan kişilerden oluşmaktadır. Bu grupta değerlendirilenler hem iş hayatlarına dair hem de yaşamları ile ilgili plansız hareket etmektedir (Pilz ve ark., 2015, s. 86). Hal böyle olunca bu grubun içerisinde bulunanlar, nispeten daha tutucu ve katı işleyişe sahip şirketlerde çalışmaktan da kaçınmaktadır (Rahman, 2007, s. 3).

Alternatifi olmayan freeter grubunda değerlendirilenler ise, mezuniyet sonrasında başka seçeneği olmayan kişilerdir. Bu grup içerisinde bulunanlar uygun bir kariyer hedefi için gerekli olan beceri, firsat ve motivasyondan yoksun kişilerden oluşmaktadır. Hayatının sonraki dönemlerinde uygun bir kariyer bulacaklarını düşünen bu kişiler; düşük vasıflı, düşük ücretli, sosyal güvenceden yoksun süpermarketlerde, fast-food restoranlarında vb. yerlerde çalışmaktadır. (CrossCurrents, 2021; Rahman, 2007, s. 3; Pilz ve ark., 2015, s. 86).

Hayallerinin peşinde koşan freeterler ise belirli bir istihdam hedefi olan (şarkıcı, oyuncu vb. olmak) kişilerden oluşmaktadır. Daha çok birinci gruba benzeyen bu grup içerisindekiler bir anlamda hayattan zevk almaya meyillidir. Hayalleri, sıradan çalışma dinamikleriyle uyuşmayan bu grup, freeter olmayı tercih etmektedir (Rahman, 2007, s. 3; Pilz, ve ark., 2015, s. 86; CrossCurrents, 2021).

Japonya genelinde 2003 y1linda 2,17 milyon olan freeter sayıs 2010 y1lı itibariyle 1,83 milyon seviyelerine gerilemiştir (Ueda ve Ohzono, 2013, s. 100). 2014 yılına gelindiğinde 1,79 milyona kadar gerileyen freeter sayısı 2020 y1lı hedeflerinde 1,24 milyon olarak öngörülmüştür (The Japan Institute for Labor Policy and Training, 2017, s. 100). Birebir aynı kavramsal çerçevede değerlendirilmese de birçok Avrupa ülkesinde, Çin'de ve diğer Uzak Doğu ülkelerinde de benzer şekilde çalışanların oranının arttığı ifade edilmektedir (Soetanto ve Zhou, 2010, s. 267). 
Freeterler güvencesiz, düşük ücretli, vasıfsız ve geçici işlerde çalıştıkları için bir anlamda "Prekarya" olarak da nitelendirilebilir. Sosyal güvencelerden mahrum olan ve işlerinin devamlılığı olmayan freeterler a-tipik istihdamın içerisinde yer almaktadır (Suwa ve Suzuki, 2013, s. 197). Bu bağlamda 2000'li yıllarda Japon gençlerinin istihdamda yaşadıkları sorunlar nedeniyle kurduğu genç-güvencesiz işçi sendikası (General Union for Freeters/ Furìtā Zenpan Rōdō Kumiai), freeterlerin sorunlarının anlaşılması açısından oldukça önemlidir (Standing, 2014, s. 25).

Sonuç olarak freeter vb. işgücü piyasasındaki dezavantajlı grupların dijital çağın zayıf yönleri ve tehditlerine karşı korunması gerekmektedir. Zira dijital çağda yetenekli ve yeteneksiz bireyler arasındaki makas açılacak, bu durum uzun vadede toplumun kutuplaşmasına ve orta sınıfın oyulmasına neden olacaktır. Aynı şekilde meslek ve statülerin zaman içerisinde prekaryalaşması, orta vasıflı işlerde çok fazla bilgisayarlaştırma gibi gelişmelerin olumsuz sonuçları olacaktır (Coşan, 2020, s. 238-239). Bu durum freeter vb. düşük vasıflı kişilerin işlerini kaybetmesine ve bu kişilerin sayıca artmasına neden olacaktır. Bu bağlamda dijital çağın riskleri ve tehditleri de yine aynı şekilde Toplum 5.0'ın kendi iç dinamikleriyle çözülmeli, işgücü piyasasındaki dezavantajlı bireylerin yetkinliklerini teknolojik imkânlarla geliştirecek sosyal politikalar hayata geçirilmelidir.

\section{Psiko-Sosyal Bir Sorun Olarak Japonya'da Hikikomori: Kültürel mi Evrensel mi?}

Kelime köken olarak, Japonca "hiku” ve "komoru” fillerinin birleşiminden türetilmiştir. Hiku Japonca'da "geri çekilme", komoru ise "(içe) kapamak/ kapanmak" anlamlarına gelmektedir (Nesser, 2009, s. 13). Kavram yakın zaman içerisinde sözlüklerde, uluslararası sosyal medyada, video kliplerde, filmlerde, Japon animasyonlarında ve makalelerde sıklıkla kullanılmaya başlanmıştır (Yong ve Kaneko, 2016, s. 2). Yapılan bir çalışmada Japonya'da hikikomorinin yaşam boyu yaygınlık oranı toplam nüfus içerisinde \% 1,2 olarak tespit edilmiştir (Koyama ve ark., 2010). Çeşitli anketler ve yapılan hükümet çalışmalarında ise hikikomori olanların sayısının 500.000 ile 2.000 .000 arasında olduğu tahmin edilmektedir (Ismail, 2020, s. 698). 2016 y1lında hükümetin yayınladığı raporda bu sayının en az 541.000 (15-39 yaş arası) olduğu tahmin edilmektedir (Tajan, Yukiko, ve Pionnié-Dax, 2017, s. 1). 
Hikikomori (sosyal geri çekilme/social withdrawal), gençlerin toplumla her türlü teması reddettiği ve tüm sosyal faaliyetlerden çekildiği davranış kalıbı olarak tanımlanabilir. Hikikomori kelimesi hem fenomeni hem de bundan muzdarip olan kişileri tanımlamak için kullanılmaktadır. Bu durum 1990’lardan beri çoğunluğu gençler olmak üzere 40’lı yaşlara kadar toplumdaki birçok kişiyi etkilemektedir. Zaman içerisinde hikikomori, Japonya'da yeni bir sosyal sorun olarak hatırı sayılır derecede ilgi odağı haline gelmiştir. Hikikomori, lise ve üniversiteden mezun olan ya da okulu bırakan/eğitimini tamamlayamayan genç yetişkinlerin işe gir(e)medikleri, toplumla ilişkilerini kestikleri ve hayatlarını esas olarak aile evleriyle sınırladıkları bir durum olarak da değerlendirilebilir (Suwa ve Suzuki, 2013, s. 191). Bazı örneklerde, hikikomorili gençlerin diğer aile üyeleriyle konuşmadığı zaman zaman kapı eşiğinden iletişim kurduğu (Forsberg, 2012, s. 2), gündüz tüm gün uyudukları, geceyi ise uyanık geçirdikleri bilinmektedir. Bazı gençler, kütüphaneye gitmek, yakın çevrede alışveriş yapmak gibi aktivitelerde bulunsa da genellikle bu gençlerin evlerini terk etmedikleri hatta odalarından hiç çıkmadıkları bilinmektedir (Suwa ve Suzuki, 2013, s. 191). Birtakım araştırmacılar hikikomorinin psikiyatrik bir bozukluğun parçası olmadığını, ergenlik dönemi zorlukları ve Japonya'da hızlı değişim gösteren sosyal ve ailevi yapının etkileşiminden kaynaklandığını ifade etmektedir. Bu durum daha çok "birincil hikikomori" olarak tanımlanmaktadır. Diğer yandan Japonya' da halk sağlığı merkezine başvuran hikikomorili kişilerde sosyal fobi, obsesif kompulsif bozukluk, sanrısal bozukluk, somatik bozukluk, dikkat eksikliği/hiperaktivite bozukluğu, depresif bozukluk vb. psikiyatrik sorunların (ikincil hikikomori) olduğu da bildirilmiştir. Ayrıca bu kişiler hangi durumun (hikikomori mi yoksa diğer sorunlar mı) daha önce meydana geldiğini ifade etmemişlerdir. Ancak Ukrayna özelinde yapılan bir çalışmada ise birincil ve ikincil hikikomorinin karakteristiğinin büyük oranda birbirine benzediği sonucuna ulaşılmıştır (Frankova, 2019, s. 6). Hal böyle olunca psikiyatrik bozuklukların hikikomorinin gelişmesine nasıl etki ettiğini bilmek de konunun başka bir boyutu olarak karşımıza çıkmaktadır. 2003 yılında Japon Hükümeti'nin yaptığı tanımlamada hikikomorinin sınırları gençlerde (Kawanori ve Kambara, 2018, s. 54) şu şekilde çizilmiştir:

- Genelde evde kalmaları

- Okula gitmek ya da çalışmak gibi sosyal aktivitelerde bulunmamaları

- Bu durumun 6 aydan fazla sürmesi 
- Psikotik patolojiye veya orta/düşük seviyeli zeka geriliğine sahip olmamaları (IQ<50-55) (Suwa ve Hara, 2007, s. 95).

Japonya dışındaki birçok ülkede de hikikomori durumundaki bireylerle alakalı çalışmalar mevcuttur. Örneğin; Güney Kore, -daha bireysel vakalarda veya daha az oranda görülmelerine rağmen (çoğunlukla kentte)- Kanada, Fransa, İtalya, Brezilya, İspanya, Ukrayna, Finlandiya, Hong-Kong, Tayvan, Bangladeş, İran, Hindistan, Tayland, Avustralya, ABD ve Asya’nın diğer kısımlarında da hikikomori durumundakilerin varlığını gösteren çalışmalar mevcuttur (Suwa ve Suzuki, 2013, s. 193; Malagón-Amor ve ark., 2015, s. 475; Ovejero ve ark., 2013, s. 562; Teo, 2013, s. 339; Sakamoto ve ark., 2005, s. 191; Haasio ve Naka, 2019, s. 509; Frankova, 2017; Kato ve ark., 2012, s. 1075; Wong ve ark., 2015, s. 330; De Luca, 2020, s. 3; Stip ve ark., 2016, s. 1, Roza ve ark., 2021, s. 1). Bu duruma ilk olarak Birleşik Krallık'ta kullanılan NEET kavramının, daha sonraları birçok ülkede kullanım alanı bulması örnek gösterilebilir. Örneğin, ABD'de de "slacker", "twixter" ve "adultolescant" gibi kavramlar da gençlerin ebeveynleriyle bir arada yaşadığı ve bağımsız olamadıkları durumu ifade etmek için kullanılmaktadır (Li ve Wong, 2015, s. 595). Özetle, hikikomorinin hem aynı formda hem de yakın formlarda başka ülkelerde de olduğunu ve bu durumun sadece Japonlara has bir durum olmadığını söylemek mümkündür.

Japonya'da 1990'larda başlayan ekonomik durgunluğun da -ki bu dönem Japonlar arasında ushinawareta jünen (kayıp on yıl) olarak nitelendirilmektedirhikikomori üzerinde etkili olabileceği ifade edilmektedir (Nesser, 2009, s. 16-18). Ekonomik sebeplerin dışında, karşılıklı anne-oğul ilişkileri, ailenin etkisi, ailenin çocuktan beklentileri, okuldaki başarısızlıklar gibi sebepler hikikomorinin tetikleyicisi olabilmektedir. "Hitorikko" (doğum oranlarının azalması) ve "Tōkōkyohi" (okulu birakma/okul fobisi) vb. problemler de bu sürecin yaşanmasında belirleyici olabilmektedir (Dziesinski, 2003, s. 16). Ayrıca okulu reddetme/okuldan kaçma, devamsızlık anlamlarına gelen "futōko" da hikikomori üzerinde etkili olan diğer bir faktördür. Futōko, Japonya'da 1970'lerden beri sosyal bir problem olarak devam etmektedir. Psikiyatristlerin, psikologların ve psikoterapistlerin 1980'lerde sıklıkla üzerinde çalıştığ bu konu, 1990'larda psikiyatrik seviyenin ötesinde daha karmaşık bir sosyal sorun olarak kabul görmeye başlamıştır. Futōko, hastalık ya da ekonomik zorluklar dışında, birçok nedene bağlı olarak bir akademik yılda 30 günden fazla yapılan 
devamsızlığı ifade etmektedir (Yamada, 2015, s. 1). Hikikomorinin ortaya çıkmasında etkili olan bir diğer etmenin de Japonya'daki amae kültürü olduğu savunulmaktadır (Nesser, 2009, s. 31). Amae; çocukların ebeveynlerine, gençlerin büyüklerine, büyükanne ve büyükbabanın yetişkin çocuklarına vb. bağl1 olduğu uyumlu ilişkileri sürdürmenin temelini oluşturmaktadır. Doğrudan İngilizce'ye çevrilemeyen bu kavram Avrupa dillerinin hiçbirinde doğrudan eş değere sahip bir kavramla açıklanamamaktadır. Tanımlaması oldukça karmaşık bir kavram olan amae, otorite figürlerine (dikey) ve sosyal ilişkilere (yatay) kökleşmiş bir bağlılı̆̆ ifade etmektedir. Diğer yandan amae, "hoşgörü ve kabul" olarak tanımlanmaktadır. Japon kişilik yapısının anlaşılmasında anahtar bir kavram olan amae, "başkalarının iyiliğine bağlılık”olarak da ifade edilebilir. Amae kavramı Japon yaşamının tüm yönlerini büyük ölçüde etkilemektedir. Çünkü bu kavram diğer Japon düşünce tarzlarıyla yakından ilişkilidir. Örneğin; kısıtlama (enryo), sosyal yükümlülük (giri), günah (tsumi), utanç (haji) gibi kavramlar amae ile doğrudan ilişkilidir (Davies ve Ikeno, 2002, s. 17-21).

Zaman zaman NEET (Ne eğitimde ne istihdamda bulunanlar/Not in Employment, Education or Training) ve hikikomori kavramları birbirinin yerine kullanılabilmektedir. Ancak bu iki kavramın birbirinin yerine kullanılması doğru bir yaklaşım olmayacaktır. NEET kavramı daha çok işgücü piyasasıyla ilgili sebeplerle ortaya çıkarken, hikikomori ise çok daha karmaşık nedenlere dayanmaktadır (Suwa ve Hara, 2007, s. 95). Ne istihdamda ne eğitimdeki kişilerin içerisinde değerlendirilen, "iş bulma ümidini kaybetmiş/gücenmiş" (discouraged/disengaged) kişiler ise bir süre sonra psikolojik olarak bu durumdan etkilenip toplumdan soyutlanabilmektedir. Bu yönüyle ne istihdamda ne eğitimde bulunanların bazı alt gruplarının uzun vadede hikikomori riskiyle karşı karşıya kalabileceğini söylemek daha yerinde bir yaklaşım olacaktır.

Yapılan çalışmalarda hikikomori semptomlarıyla internette oyun oynama bozukluğu (internet gaming disorder) arasında da ilişki olduğu tespit edilmiştir (Stavropoulos ve ark., 2018, s. 1). Bir başka çalışmada da Japon gençlerinin internet bağımlılığı, akıllı telefon bağımlılığı ve hikikomori riski arasında ilişki olduğu gözlemlenmiştir (Tateno ve ark., 2019, s. 8). Bu durumun ise çift yönlü değerlendirilmesi daha doğru bir yaklaşım olacaktır. Zira hikikomori durumundakiler odalarında gece-gündüz internet, oyun vb. aktivitelerle meşgul olurken diğer yandan oynanan online oyunlar, izlenen animeler de hikikomori 
durumunu tetikleyebilmektedir. Kato ve arkadaşları bu durumu "tavuk-yumurta" ikilemi şeklinde ifade etmektedir (Kato, Shinfuku ve Tateno 2020, s. 264).

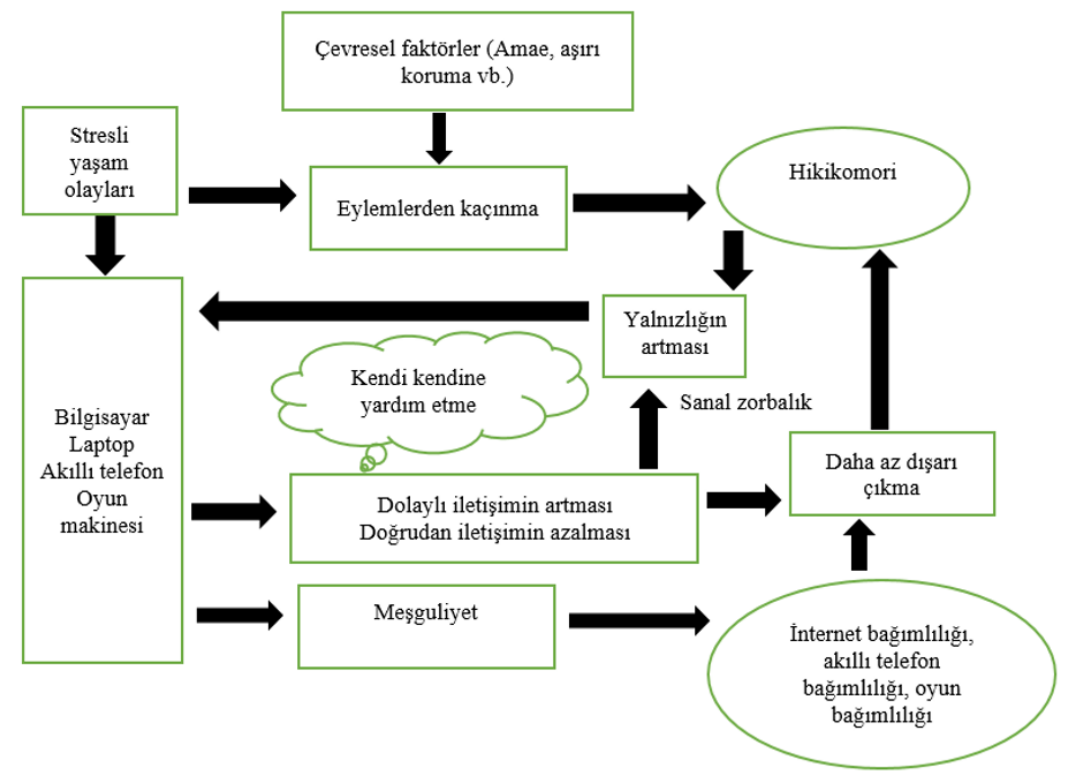

Şekil 1. İnternet Toplumu, İnternet Bağımlılığı ve Hikikomori Döngüsü

Kaynak: (Kato, Shinfuku ve Tateno 2020, s. 267) verilerinden düzenlenerek hazırlanmıştır.

Şekilden görüldüğü üzere internet kullanımı ve hikikomori arasında çift taraflı bir ilişki olduğu görülmektedir. Zira internet, bilgisayar vb. aktivitelerle fazla ilişkili olan bireyler zaman içerisinde insanlarla doğrudan iletişimi azaltıp dolaylı iletişim kurmayı tercih etmektedir. Bu durum da uzun vadede yalnızlı̆̆ın artmasına ve hikikomori durumunun oluşmasına neden olmaktadır. Bu durumun tam aksine Japon menşeili Pokemon $\mathrm{Go}^{4}$ oyunun ise hikikomori durumunda olan gençlerin izole olan odalarından çıkmaları için bir firsat olacağı ifade edilmektedir (Kato ve ark, 2017, s. 75-76).

Japonya özelinde yapılan başka bir çalışmada, hikikomori artışının sosyoekonomik (işsizlik) faktörlerden etkilendiği sonucuna ulaşılmıştır. Hal böyle olunca bir yandan bireysel ve kültürel faktörler hikikomoride belirleyici olurken diğer yandan sosyo-ekonomik faktörlerin de sürece dahil edilmesinin gerekliliği ifade edilmiştir (Nonaka ve Sakai, 2020, s. 2). Bir diğer çalışmada, akran reddi/zorbalığının

4 Pokemon Go artırılmış gerçeklik mantığı üzerine kurulu bir oyundur. Oyun, belli adreslere gidip ilgili Pokemonların toplanması ve koleksiyonların tamamlanması mantığına dayanmaktadır. Oyunun lokasyon temelli olması bireylerin evden çıkmalarını zorunlu hale getirmektedir 
ve ebeveyn reddinin hikikomoriye neden olduğu gözlemlenmiştir. Bu durumdaki bireylerde mizaç olarak utangaçlık seviyesinin de yüksek olduğu ifade edilmiştir (Krieg ve Dickie, 2011, s. 61). Aynı şekilde ebeveynlerle iletişim düzeyi de hikikomorinin belirleyicileri arasındadır (Hamasaki ve ark., 2020). Bu çerçevede aile davranış ilişkileri ve aile etkileşimi ile ilgili bilişsel davranış faktörlerinin hikikomorideki iyileşme ile ilişkili olduğunu gösteren çalışmalar mevcuttur (Nonaka, Shimada ve Sakai, 2020, s. 1). Ayrıca hikimori ile fiziksel sağlık arasındaki ilişkinin önemine de vurgu yapılmaktadır. Örneğin, Hong-Kong'da gençler üzerinden yapılan bir çalışmada, hikikomori durumundaki gençlerde kilo artışı gözlemlenmiştir. Bu durum, gençlerin hipertansiyon ve prehipertansiyon insidansına ${ }^{5}$ sahip olduklarını ortaya koymaktadır. Hikikomori süresi uzayan gençlerde vücut ağırlı̆̆ının arttığı ve bu durumun uzun vadede obeziteye neden olduğu görülmüştür. Sağlıksız beslenme alışkanlıkları ve düzensiz uyku nedeniyle görülen bu sorunlar hareketsiz bir yaşam tarzının sonucu olarak ortaya çıkmaktadır (Yuen ve ark., 2018, s. 7). Özetle hikikomori, kültürel kodların ötesinde çok daha interdisipliner bir alanın konusudur (Berman ve Rizzo, 2019, s. 791). Yapılacak olan çok boyutlu çalışmalarla hem Japonya'da hem dünya genelinde artan hikikomori farkındalığı, araştırmacılar, klinisyenler ve politika yapıcılar açısından yararlı kanıtlar sağlayabilir (Pozza ve ark., 2018, s. 6). Bu sebeple hikikomori ile ilgili tedavi sürecinin de çok boyutlu değerlendirilmesi gerekmektedir.

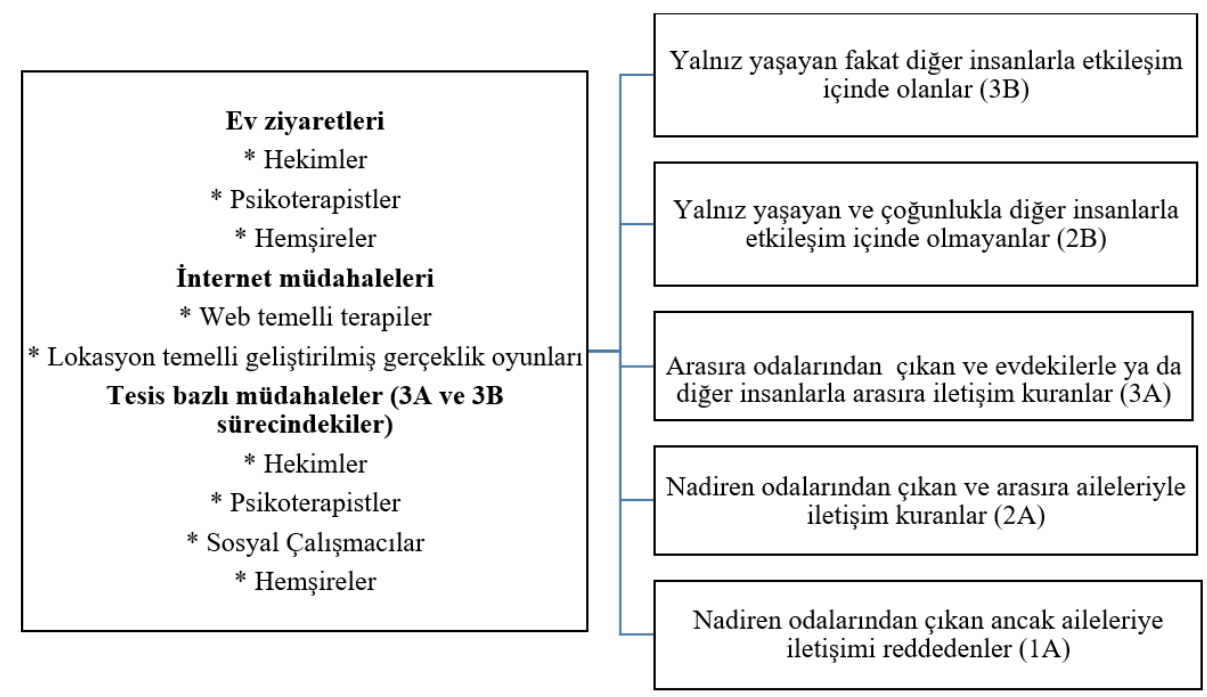

Şekil 2. Hikikomori için Çok Boyutlu Tedavi Yaklaşımları

Kaynak: (Kato ve ark., 2017, s. 2012) verilerinden düzenlenerek hazırlanmıştır.

5 Bir hastalığın belli bir zaman aralığında görülen yeni olgularının sayısı insidans olarak tanımlanmaktadır. 
Yukarıdaki şekilden görüldüğü üzere 1A, 2A ve 3A grubu, aileleriyle yaşayan hikikomori durumundaki bireyleri göstermektedir. 2B ve 3B grubu da yalnız yaşayan hikikomori durumundaki bireyleri temsil etmektedir. Sol tarafta genel olarak bütün gruplar için uygulanabilecek yaklaşımlar gösterilmeye çalışılmıştır. Burada aileleriyle yaşayan bireyler için psikoeğitim, Ruh Sağlığı İlk Yardımı (Mental Health First Aid/MHFA), Destek ve Aile Yardımı (Reincforcement and Family Training/CRAFT) gibi faaliyetler yürütülmektedir. Ayrıca yalnız yaşayanlar için de web temelli terapiler ve lokasyon temelli geliştirilmiş gerçeklik oyunları destek açısından faydalı olabilmektedir (Kato ve ark., 2017, s. 212).

COVID-19 salgını sonrası yaşanan gelişmelerden sonra, bilim insanlarının salgının akıl sağlığı üzerindeki etkilerini araştırmaya başlaması, hikikomori meselesinin de pandemi bağlamında değerlendirilmesini gerekli hale getirmektedir (Kato, Sartorius ve Shinfuku, 2020). Ampirik verilerle alakalı eksiklikler olmasına rağmen, COVID-19 pandemisi sonrasında artabilecek hikikomori riski karşısında uzmanlar teyakkuzda olmalıdır. Bu süreçte evde egzersiz yapmak, ekran süresini azaltmak, sağlıklı diyeti sürdürmek gibi yaşam tarzlarının benimsenmesi, daha iyi zihinsel davranışların geliştirilmesi açısından önem arz etmektedir. Pandemi sonrasında ebeveynlerin, açık hava etkinlikleri ve yüz yüze etkileşimi teşvik etmesi de oluşabilecek olumsuz sonuçların etkilerini azaltmak açısından önemlidir (Roza ve ark., 2021, s. 1-2). Zira pandemi sürecinde hikikomori vb. sorunlardaki artış1 "sessiz pandemi" olarak nitelendirmek yanlış olmayacaktır (Silić ve ark., 2019, s. 317; Roza ve ark., 2020, s. 2). Japon hükümetinin güncel tahminlerine göre 15-64 yaş arası 1,15 milyon hikikomori durumunda birey olduğu tahmin edilmektedir. Uzman Saitō Tamaki ise bu sayının zaman içerisinde 10 milyonun üzerine bile çıkabileceğini ifade etmektedir (Nippon, 2019). Bu veriler "sessiz pandemi” söylemini doğrular niteliktedir.

\section{Japonya'da Sosyal Sorun Olarak Yaşlı Nüfus ve Evlen(e)meyen Bireyler}

Japonya, Monako Prensliğinden sonra dünyada en yaşlı nüfusa sahip ikinci ülke konumundadır. 2019 yılı verilerine göre dünya nüfusunun \% 9,09’u (65+) yaşlı nüfus olarak tahmin edilmektedir. Japonya nüfusu içerisindeki yaşlı nüfus oranı ise 2020 Ekim verisine göre \% 28,7 seviyesindedir (WorldBank, 2021c; Statistics Bureau of Japan, 2021b). 1970'lerden sonra birçok Asya ülkesinde 
ilk evlilik yaşı ortalamasının artışı ve azalan doğum oranlarına bağlı olarak yaşlı nüfus oranında da ciddi artışlar yaşanmıştır. Bu süreçte kültürel değerlerde yaşanan değişimler, evlilik dinamiklerinin de değişmesine neden olmuştur. Evlilikte "geç ya da asla" ilkesinin yaygınlaşması -Japonca' da geç evlilik bankon, ömür boyu evlenmemek ise shōgai mikon jidai olarak bilinir- uzun vadede demografik verilerin değişmesine neden olmuştur (Retherford, Ogawa, ve Matsukura, 2001, s. 65; Saardchom ve Lemaire, 2005, s. 76). Örneğin, 2019 y1lı verilerine göre erkeklerde 31,2 olan ortalama ilk evlilik yaşı, kadınlarda 29,6 seviyelerine kadar yükselmiştir (Statista, 2021). 2015 y1lı verilerine göre 50 yaş altında her 4 erkekten 1'i ve her 7 kadından 1'inin hala evlenmemiş olduğu bilinmektedir (Japantimes, 2017a). 2018'de Birleşik Krallık'ta kurulan Yalnızlar Bakanlığı'nın peşine, COVID-19 pandemisi sonrası Japonya, aynı bakanlığı kuran ikinci ülke olmuştur. Japon Başbakanı Yoshihide Suga, sosyal izolasyonun önlenmesi için böyle bir çalışma başlatılmasının gerekli olduğunu ifade etmiştir. Özellikle pandemi sürecinde Japonya'da kadınlarda artan intihar oranları, yalnızlık sorunun incelenmesini gerekli hale getirmiştir (NikkeiAsia, 2021).

Japonya'da artan yaşlı nüfusla beraber yalnız yaşayanların ölümlerinde de artış görülmeye başlanmıştır. Japonya'nın geçmişinde, yaşlı ebeveynlerin geniş aile formu içerisinde güçlü bir yetişkin-çocuk geleneği içerisinde yaşadığ 1 bilinmektedir. Artan şehirleşme ve buna bağlı olarak çekirdek ailenin baskın hale gelmesiyle birçok yaşlı çift yalnız yaşamaya başlamıştır. Zira 2017 yılı Başbakanlık Yaşlı Toplum Yı1lığı verilerine bakıldığında 65 yaş üstü yalnız yaşayanların sayısının yıllar itibariyle arttığı görülmektedir. 1980 yılında 65 yaş üstü yalnız yaşayanların sayısı erkeklerde 193.000 kişi, kadınlarda ise 688.000 kişidir. 2015 yılına gelindiğinde 65 yaş üstü 1,92 milyon erkek ve 4 milyon kadın yalnız yaşarken bu sayının 2040 yılında erkeklerde 3,5 milyona kadınlarda 5,4 milyona yükseleceği tahmin edilmektedir (Japan Cabinet Office, 2021b). Bu minvalde çoğunlukla iki partner de hayattayken çok fazla sorun yaşanmazken, bir partnerin ölümüyle beraber yaşlı bireyler yalnız kalma riskiyle karşı karşıya kalmaktadır. Eşlerin hayatta olduğu durumda çoğu zaman günlük yaşam aktivitelerine devam edilmekte ancak yalnız yaşayanlarda ise bilişsel gerileme, bunama ve fiziksel engeller gibi olumsuzluklar geliştikçe hayat çok daha zor bir hal almaktadır. Yalnız yaşayan yaşlılar sorunu, bu sebeple Japonya'da önemli bir sosyal sorun olarak görülmektedir. Yalnız yaşayan yaşl1lar çoğu zaman hiçbir sosyal temas olmadan haftalarca hatta aylarca 
evlerinde kalabilmektedir. Ölüm durumunda bile çoğu zaman ölen kişi birkaç hafta/ay çevredekilerce farkedilmemektedir. Japonca'da bu durum kodoku-shi (yalnız ölüm) olarak isimlendirilmektedir (Kato ve ark., 2017, s. 206). Gün geçtikçe sayıları katlanarak artan kodoku-shi'ler önemli birer sosyal sorun olarak değerlendirilmektedir. Her ne kadar teknolojinin gelişimine bağlı olarak yaşlılara yönelik bakım hizmetlerinde ilerleme kaydedilse de Japonya'nın yaşlanan nüfusunun psiko-sosyal ve ekonomik sonuçları artarak devam edecektir (Erol, 2013, s. 47-63).

Bir diğer önemli grup ise parazit bekârlar (parasaito shinguru/parasite single)'dır. Kavram ilk defa 1997 yılında yazar Yamada Masahiro'nun eserinde kullanılmıştır (Lunsing, 2003, s. 261). Genellikle hikikomori ile karıştırılan bu durum, birebir hikikomori ile örtüşmemektedir (Bowker, 2016, s. 22). Parazit bekârlar, evlerine katkıda bulunmayan, tüm paralarını alışverişe ve kendi eğlencelerine harcayan asalaklar (leeches) olarak görülmektedir. Bu grubun 2000'lerin başında 13 milyondan fazla olduğu tahmin edilmektedir. Bu gruba karşı olumsuz bakış açısının oluşmasının sebebi, daha az evlilik ve daha az doğum endişesinden kaynaklanmaktadır. Japonya'nın giderek düşen doğum oranları ve mevcut sosyal sıkıntılarından zaman zaman bu grup sorumlu tutulmaktadır (Nesser, 2009, s. 23). 2016 yılında yapılan bir araştırmada 35-54 yaş arası ebeveynleriyle yaşayan, evli olmayan, işsiz ya da eksik istihdamda 4,5 milyon parazit bekârın olduğu tahmin edilmektedir (Independent, 2017). İçinde bulundukları durum itibariyle dezavantajlı durumda olan bu grup, hükümet tarafından düşen doğum oranları ve ekonomik durgunluğun büyük bir sebebi olarak görülmektedir. Zira bu grubun içinde olanların kendi bağımsız hanelerini kurmamaları ve sadece kendi ihtiyaçları için tüketime odaklanmalarının kültürel anlamda durgunluğa sebep olduğu ifade edilmektedir (Japantimes, 2000). Bu grup ayrıca sosyal refah sistemine yük olmaları ve mevcut işgücü hacminini küçültmeleri nedeniyle de eleştirilmektedir. Ancak bu kişilerin bir kısmı evlenmek istedikleri halde düzenli iş bulamadıkları için evlenemediklerini ifade etmektedir. Ebeveynleriyle yaşayan bazı yaşı ilerlemiş bekârların ise bir kısmının geçmişte sabit işinin olduğu bilinmektedir. Şirketlerin zaman içerisinde maliyetleri düşürmek adına işçi çıkarmaları ya da bu kişilerin bir kısmının hastalık nedeniyle işlerinden ayrılmaları gibi sebeplerden dolayı da bu bireyler aileleriyle yaşamak durumunda kalmıştır. Sonuç olarak ebeveynleri sağ iken bir nebze daha rahat olan parazit bekârlar, ebevenylerinin vefatından sonra birer saatli bomba olarak değerlendirilebilir. Zira bu kişilerin uzun süre yalnız 
kalmaları bir süre sonra hikikomori durumuna düşmelerine neden olabilmektedir (Japantimes, 2017b).

\section{Sonuç}

Toplum 5.0 hedefleriyle dünyaya örnek olmak isteyen Japonya, bu söylemin mimarı olmakta haklı sebeplere sahiptir. Yaşanan demografik değişimler sebebiyle (yaşlanan nüfus, azalan doğum oranları vb.) Japonya açısından mevcut nüfusun azami refahının sağlanması elzem hale gelmektedir. Japonya bu refaha ulaşmanın Toplum 5.0 enstrümanlarıyla mümkün olacağını ifade etmektedir. Hal böyle olunca refahın toplumun geneline yayılmasında teknolojinin çok etkin rol oynayacağı unutulmamalıdır. Bu sebeple yalnız kalan yaşlıların, ekonomik anlamda dezavavantajlı olan freeterlerin, parazit olarak nitelendirilen bekârların ve hikikomori durumundaki bireylerin dezavantajl1lığının giderilmesinde Toplum 5.0 felsefesinin çok büyük bir öneme sahip olduğu unutulmamalıdır. Japonya'nın ise kronikleşen bazı problemlerine karşı (yaşlanan nüfus, azalan doğurganlık oranları, freeter, hikikomori vb.) Toplum 5.0 argümanlarının ne kadar yeterli olacağını zaman gösterecektir. Zira Toplum 5.0 söylemiyle oldukça iddialı hedefler ortaya koyan Japonya'nın, dezavantajlı gruplarında hedeflediği iyileşmeyi yakalaması kısa vadede mümkün gözükmemektedir. Çünkü Japonya'da evlilik ve yaşlılıkla ilgili sorunların yapısal bir forma büründügü görülmektedir. Bu durum da sorunların kısa vadede çözümünü zorlaştırmaktadır. Zira evliliğe bakışla alakalı algının Toplum 5.0'la belirlenecek refah hizmetleriyle çözülmesi oldukça zordur. Burada birtakım evliliği teşvik edici unsurların ne derece işe yarayacağ şekilde azalan doğurganlık oranlarının artırılmasına yönelik birçok ülke gibi Japonya da çeşitli politikalar uygulamakta ancak doğurganlığı arzu edilen seviyelere getirememektedir. Bu bağlamda Toplum 5.0'ın imkânlarıyla yaşlıların refahını artırmak çok daha önemli hâle gelmektedir. Örneğin gelişen teknolojilerle yaşlıların nabız, tansiyon, EKG vb. fiziksel değerlerinin anlık takibi ya da psikolojik sorunlarına karşı çevirimiçi danışmanlıklar sunulmasının zaman içerisinde yaygınlık kazanması gerekmektedir. Ayrıca gelişen teknolojik cihazlarla (drone vb.) evlere hizmetin yaygınlaşması da yaşlılar açısından oldukça verimli olacaktır. Yine aynı şekilde hikikomori durumundaki bireylere çevirimiçi teknolojik destek sağlamak bu anlamda oldukça önemlidir. İşücü piyasasındaki freeter durumundaki bireylerin de yetkinliklerinin artırılması ve mevcut becerilerinin geliştirilmesi adına teknolojik imkânlardan faydalanılması, 
teknolojik mesleki eğitimler verilmesi bu kişilerin niteliklerinin artırılmasına katkı sağlayacaktır. Özetle Toplum 5.0 felsefesi, Japon toplumunun birtakım dezavantajlı gruplarına çok büyük fayda sağlayacak ancak kronik bazı sorunlara kalıcı çözüm olamayacaktır.

Son olarak çalışmaya konu olan sorunların Türkiye'deki mevcut izdüşümlerinin resmedilmesi de bu çalışma açısından önemlidir. Bundan sonraki çalışmalarda Türkiye'de özellikle COVID-19 pandemisi sonrası işini kaybeden vb. sebepler nedeniyle içe kapanan ve kendilerini toplumdan soyutlayan gençler üzerinden bir çalışma yapılması oldukça önem arz edecektir. Bu süreçte insanların iletişiminin azalması, yalnızlaşması, sosyal ilişkilerin azalması, evlerine kapanması gibi sorunlar böyle bir çalışmanın yapılmasını elzem hale getirmektedir. Örneğin, Türkiye'de iş bulma ümidi olmayan/ gücenmiş gençlerin (15-24 yaş arası) sayısı 2019 yılında 159.000 iken 2020 yılında 318.000 'e yükselmiştir. 15 ve daha yukarı yaş grubunda ise bu sayı 1,36 milyona ulaşmıştır (TÜİK, 2021b). İşsizlik sorunu bir yana, iş bulma ümidini kaybeden kişiler de bu anlamda uzun vadede psiko-sosyal risklerle karşı karşıya kalabilmektedir. Pandemi sonrası işgücü piyasasında yaşanan sorunlar (işsizlik, yarı zamanlı ve düşük ücretlerle güvencesiz çalışma, iş bulma ümidini kaybetme vb.) ve bu sorunların bir sonucu olarak ortaya çıkabilecek olan psikolojik sorunlar (toplumdan soyutlanma, eve kapanma, aşırı internet/ bilgisayar/telefon kullanımı, depresif problemler vb.) bundan sonraki süreçte "sessiz bir pandemi"nin ayak seslerinin habercisi olacaktır. Bu çalışmayla benzer olarak Türkiye açısından önem arz eden bir diğer husus da nüfusun yaşlanmasıdır. Türkiye her ne kadar gelişmiş ülkeler kadar yaşlı nüfus oranına sahip olmasa da son yıllarda yaşı nüfus oranının artış eğiliminde olduğu görülmektedir. Türkiye'de yaşlı nüfus son beş yılda \% 22,5 artmıştır. 2015 yılında yaklaşık 6 milyon 495 bin olan yaşı nüfus, 2020 yılında 7 milyon 953 bine yükselmiştir. 2015 yılında toplam nüfus içerisindeki yaşlı nüfus oranı $\%$ 8,2 iken 2020 yılında bu oran \% 9,5 seviyesindedir (TÜİK, 2021a). Artan yaşl1 nüfus problemi demografik, (Y1lmaz, 2021, s. 64), ekonomik, sosyal güvenlik vb. sorunların ortaya çıkmasına neden olabilir. Türkiye açısından önemli bir diğer bir konu da ortalama ilk evlilik yaşının artışı ve doğurganlık hızının düşmesidır. Türkiye' de dönem dönem dalgalanmalar olsa da son yıllarda kaba evlenme hızında sistematik bir şekilde azalmanın yaşandığı görülmektedir. 2008 yılında \%o 9,04 olan kaba evlenme hızı 2020 yılında \%o 5,84'e kadar gerilemiştir. Ayrıca 2001 yılında kadınlarda 22,7 olan ortalama ilk evlenme 
yaş1, 2020 yılında 25,1'e, erkeklerde 2001 y1lında 26 olan ortalama ilk evlenme yaş1, 2020 yılında 27,9'a yükselmiştir. Buna bağlı olarak toplam doğurganlık hızı da düşüş eğilimindedir. 2001 yılında 2,38 olan toplam doğurganlık hızı, 2019'da 1,88'e, 2020 yılında 1,76'ya düşmüştür (TÜİK, 2021c). Neticede Türkiye'de de nüfusun kendini yenilemesi için gerekli olan 2,1 çocuk sayısının altına düşülmüştür. Bu durumun da uzun vadede belli başlı demografik sorunlara neden olacağı göz ardı edilmemelidir.

Hakem Değerlendirmesi: Dış bağımsız.

Çıkar Çatışması: Yazar çıkar çatışması bildirmemiştir.

Finansal Destek: Yazar bu çalışma için finansal destek almadığını beyan etmiştir.

Yazar Katkısı: xxxxxx

Peer-review: Externally peer-reviewed.

Conflict of Interest: The author has no conflict of interest to declare.

Grant Support: The author declared that this study has received no financial support.

Author Contributions: xxxxxxx 


\section{Kaynaklar/References}

Berman, N., \& Rizzo, F. (2019). Unlocking Hikikomori: an interdisciplinary approach. Journal of youth studies, 22(6), 791-806. https://doi.org/10.1080/13676261 .2018 .1544416

Bulut, Ö. Ü. R. (2019). Japonya ve Ekonomisi. Ayrıntı Dergisi, 7(78), 19-24.

Bowker, M. H. (2016). Hikikomori as Disfigured Desire: Indulgence, Mystification, and Victimization in the Phenomenon of Extreme Social Isolation in Japan. Journal of Psycho-Social Studies, 9(1), 20-52.

Coşan, B. (2020). Endüstri 4.0'dan Toplum 5.0'a Teknoloji ve İşsizlik. Çalışma Hayatının Geleceği kitabı içinde (s. 217-254). Ankara: Gazi Kitabevi.

CrossCurrents (2021, 8 Nisan). Freeter/Furita: Part-Time Workers in Japan. Erişim adresi: http://www.crosscurrents.hawaii.edu/content.aspx?lang=eng\&site=japan\& theme= work\&subtheme=EMPLOY\&unit=JWORK118

Davies, Roger. J., \& Ikeno, O. (2002). The Japanese Mind: Understanding Contemporary Japanese Culture. Tokyo: Tuttle Publishing

De Luca, M., Louët, E., Thompson, C., \& Verdon, B. (2020). Hikikomori: contemporary forms of suffering in the transition from adolescence to adulthood. Mediterranean Journal of Clinical Psychology, 8(2), 1-27. https://doi.org/10.6092/2282-1619/mjcp2507

Dinler, E. (2020). Endüstri 4.0 ve Toplum 5.0. B. Yılmaz (Ed.), Çalışma Hayatının Geleceği kitabı içinde ( s. 1-29). Ankara: Gazi Kitabevi.

Dziesinski, M. J. (2003). Hikikomori: Investigations into the phenomenon of acute social withdrawal in contemporary Japan. Honolulu: Hawaii.

England, C. (2017, 20 Nisan). Japan: More than four million middle-aged 'parasite singles' still live with their elderly parents. Erişim adresi: https://www.independent. co.uk/news/world/asia/japan-parasite-singles-four-million-middle-age-parents-livechildbirth-rate-unmarried-unemployed-a7692256.html

Erol, S. I. (2013). Japonya'da Yaşlılara Yönelik Sosyal Politikalar. “IŞ, GÜÇ”, Endüstri İlişkileri ve İnsan Kaynakları Dergisi, 15(3), 47-63.

Fernandes, N. (2020). Economic effects of coronavirus outbreak (COVID-19) on the world economy. Available at SSRN 3557504. 1-32.

Filippini, A. (2014, 30 May1s). Lost Generations in Giappone: Freeter, Neet e Parasite Single. Erişim Adresi: http://hdl.handle.net/10579/4551

Forsberg, J. (2012). Hikikomori in Contemporary Japan: A Perspective of Amae. Stockholms Unıversitet. Bachelor Thesis in Japanese Studies.

Frankova, I. (2017). Does hikikomori exist in Ukraine?. European Psychiatry, 41(1), 228-228. https://doi.org/10.1016/j.eurpsy.2017.01.2230

Frankova, I. (2019). Similar but different: psychological and psychopathological features of primary and secondary hikikomori. Frontiers in psychiatry, 10, 1-7. 10.3389/ fpsyt.2019.00558 
Haasio, A., \& Naka, H. (2019). An analysis of information shared on hikikomoris discussion forums. Qualitative and Quantitative Methods in Libraries (QQML), 8(4), 509-523

Hamasaki, Y., Pionnié-Dax, N., Dorard, G., Tajan, N., \& Hikida, T. (2020). Identifying Social Withdrawal (Hikikomori) Factors in Adolescents: Understanding the Hikikomori Spectrum. Child Psychiatry \& Human Development, 1-10. https://doi.org/10.1007/ s10578-020-01064-8

Ismail,R.(2020).NewstartsatNewStart:Recoveryand theworkofhikikomori.Transcultural Psychiatry, 57(5), 698-709. https://doi.org/10.1177/1363461520958337

Japan Cabinet Office. (2021a, 8 Nisan). Society 5.0. Erişim adresi: https://www8.cao. go.jp/cstp/english/society5_0/index.html

Japan Cabinet Office. (2021b, 30 Mayıs). Aging Situation. Erişim adresi: https://www8. cao.go.jp/kourei/whitepaper/w-2019/html/zenbun/s1_1_3.html

Japan Institute for Labour Policy and Training. (2017). Labor situation in Japan and its analysis: detailed exposition 2016/2017. Japan Institute for labour policy and training.

Japantimes (2017a, 5 Nisan). 1 in 4 men, 1 in 7 women in Japan still unmarried at age 50: report. Erişim adresi: https://www.japantimes.co.jp/news/2017/04/05/national/14-japanese-men-still-unmarried-age-50-report/

Japantimes. (2000, 7 Nisan). 'Parasite singles': problem or victims?. Erişim adresi: https:// www.japantimes.co.jp/community/2000/04/07/general/parasite-singles-problem-orvictims/

Japantimes. (2017b, 20 Nisan). Japan's middle-aged 'parasite singles' face uncertain future. Erişim adresi: https://www.japantimes.co.jp/news/2017/04/20/national/socialissues/japans-middle-aged-parasite-singles-face-uncertain-future/

Kasuga, N. (2005). Hope between Inside and Outside: "Freeters" in Japan. For Hope in the Economy Conference, Ithaca. 1-5.

Kato, T. A., Sartorius, N., \& Shinfuku, N. (2020). Forced social isolation due to COVID-19 and consequent mental health problems: Lessons from hikikomori. Psychiatry and clinical neurosciences, 74(9), 506-507. 10.1111/pcn.13112

Kato, T. A., Shinfuku, N., \& Tateno, M. (2020). Internet society, internet addiction, and pathological social withdrawal: the chicken and egg dilemma for internet addiction and hikikomori. Current opinion in psychiatry, 33(3), 264-270. 10.1097/ YCO.0000000000000601

Kato, T. A., Shinfuku, N., Sartorius, N., \& Kanba, S. (2017). Loneliness and singleperson households: Issues of kodokushi and hikikomori in Japan. In N. Okkels, C. B. Kristiansen, \& P. Munk-Jørgensen (Eds.), Mental health and illness worldwide. Mental health and illness in the city (p. 205-219). Springer Science + Business Media. https:// doi.org/10.1007/978-981-10-2327-9_9 
Kato, T. A., Tateno, M., Shinfuku, N., Fujisawa, D., Teo, A. R., Sartorius, N., ... \& Kanba, S. (2012). Does the 'hikikomori'syndrome of social withdrawal exist outside Japan? A preliminary international investigation. Social psychiatry and psychiatric epidemiology, 47(7), 1061-1075. 10.1007/s00127-011-0411-7

Kato, T. A., Teo, A. R., Tateno, M., Watabe, M., Kubo, H., \& Kanba, S. (2017). Can Pokémon GO rescue shut-ins (hikikomori) from their isolated world. Psychiatry Clin Neurosci, 71(1), 75-76. 10.1111/pcn.12481

Kawanori, Y. \& Kambara, M. (2018). A Survey on 'Hikikomori' in a Provincial City in Japan and Factors of the Recovery. International Journal of Humanities and Social Science, 8(5), 54-58. http://dx.doi.org/10.30845/ijhss.v8n5a6

Koçak, R. (2020). Beşinci Sanayi Devrimi Toplum 5.0 ve Yapay Zekâ Kültürü. Uluslararası Halkbilimi Araştırmaları Dergisi, 3(5), 1-17.

Kodama, S. (2021, 13 Şubat). Japan appoints 'minister of loneliness' to help people home alone. Erişim adresi: https://asia.nikkei.com/Spotlight/Coronavirus/Japan-appointsminister-of-loneliness-to-help-people-home-alone

Koyama, A., Miyake, Y., Kawakami, N., Tsuchiya, M., Tachimori, H., Takeshima, T., \& World Mental Health Japan Survey Group. (2010). Lifetime prevalence, psychiatric comorbidity and demographic correlates of "hikikomori" in a community population in Japan. Psychiatry research, 176(1), 69-74. 10.1016/j.psychres.2008.10.019

Krieg, A., \& Dickie, J. R. (2013). Attachment and hikikomori: A psychosocial developmental model. International Journal of Social Psychiatry, 59(1), 61-72. https:// doi.org/10.1177/0020764011423182

Li, T. M., \& Wong, P. W. (2015). Youth social withdrawal behavior (hikikomori): a systematic review of qualitative and quantitative studies. Australian \& New Zealand Journal of Psychiatry, 49(7), 595-609. 10.1177/0004867415581179

Lunsing, W. (2003). 'Parasite 'and' Non-parasite' Singles: Japanese Journalists and Scholars Taking Positions. Social Science Japan Journal, 6(2), 261-265.

Malagón-Amor, Á., Córcoles-Martínez, D., Martín-López, L. M., \& Pérez-Solà, V. (2015). Hikikomori in Spain: a descriptive study. International Journal of Social Psychiatry, 61(5), 475-483. 10.1177/0020764014553003

Nesser, L. (2009). Hikikomori-a generation in crisis: investigations into the phenomenon of acute social withdrawal in Japan (Master's thesis University of Oslo.). Institute of Cultural Studies and Oriental Languages (IKOS),

Nippon (2019, 17 Eylül). Japan's “Hikikomori” Population Could Top 10 Million. Erişim adresi: https://www.nippon.com/en/japan-topics/c05008/japan\%E2\%80\%99shikikomori-population-could-top-10-million.html

Nonaka, S., \& Sakai, M. (2020). Association of socioeconomic factors with hikikomori in Japan from 2010-2019: a correlational study, 1-19. https://doi.org/10.21203/ rs.3.rs-47381/v1 
Nonaka, S., Shimada, H., \& Sakai, M. (2020). Family behavioral repertoires and family interaction influence the adaptive behaviors of individuals with hikikomori. Frontiers in psychiatry, 10, 1-9. https://doi.org/10.3389/fpsyt.2019.00977

OECD (2021, 3 Haziran). Gross domestic product (GDP). Erişim adresi: https://data. oecd.org/gdp/gross-domestic-product-gdp.htm

Ovejero, S., Caro-Cañizares, I., de León-Martínez, V., \& Baca-Garcia, E. (2014). Prolonged social withdrawal disorder: a hikikomori case in Spain. International Journal of Social Psychiatry, 60(6), 562-565. 10.1177/0020764013504560

Öz, E., \& Vural, T. (2005). Ekonomisi ve Vergi Sistemiyle Japonya. Maliye Dergisi, 149, 105-123.

Özşen, T. (2011). Robot Krallığı Japonya’nın Görünmeyen Yüzü: Dünden Bugüne Japon Kırsalı. Sosyoloji Araştırmaları Dergisi. 14(2), 59-93.

Özşen, T. (2020). Modern Japon Eğitim Sisteminin Tarihi Temelleri Üzerine Değerlendirme: Meiji'den Shôwa'ya 1868-1950 Arası Döneme Bakış. Journal of Theory and Practice in Education, 16(1), 36-52. https://doi.org/10.17244/eku.690744

Pilz, M., Schmidt-Altmann, K., \& Eswein, M. (2015). Problematic transitions from school to employment: freeters and NEETs in Japan and Germany. Compare: A Journal of comparative and international education, 45(1), 70-93. https://doi.org/10.1080/0305 7925.2013.835193

Pozza, A., Coluccia, A., Kato, T., Gaetani, M., \& Ferretti, F. (2019). The 'Hikikomori'syndrome: worldwide prevalence and co-occurring major psychiatric disorders: a systematic review and meta-analysis protocol. BMJ open, 9(9), 1-8. 10.1136/bmjopen-2018-025213

Rahman, K. M. (2007). Freeters' and Part-timers' Challenge to Human Resources Management in Japan. School Journal. 1-23.

Reiko, K. (2006). Youth Employment in Japan's Economic Recovery: 'Freeters' and 'NEETs'. The Asia-Pacific Journal, 4(5), 1-5.

Retherford, R. D., Ogawa, N., \& Matsukura, R. (2001). Late marriage and less marriage in Japan. Population and development review, 27(1), 65-102.

Roza, T. H., Spritzer, D. T., Gadelha, A., \& Passos, I. C. (2021). Hikikomori and the COVID-19 pandemic: not leaving behind the socially withdrawn. Brazilian Journal of Psychiatry, 43(1), 114-116. 10.1590/1516-4446-2020-1145

Saardchom, N., \& Lemaire, J. (2005). Causes of increasing ages at marriage: An international regression study. Marriage \& family review, 37(3), 73-97. https://doi. org/10.1300/J002v37n03_05

Sakamoto, N., Martin, R. G., Kumano, H., Kuboki, T., \& Al-Adawi, S. (2005). Hikikomori, is it a culture-reactive or culture-bound syndrome? Nidotherapy and a clinical vignette from Oman. The International Journal of Psychiatry in Medicine, 35(2), 191-198.

Sığrı, Ü. (2006). Japonların kültürel özellikleri bağlamında; yönetsel, ekonomik ve sosyal süreçlerinin analizi. Ístanbul Ticaret Üniversitesi Sosyal Bilimler Dergisi, 5(9), 29-47. 
Silić, A., Vukojević, J., Čulo, I., \& Falak, H. (2019). Hikikomori silent epidemic: a case study. Research in Psychotherapy: Psychopathology, Process, and Outcome, 22(2), 317-322. 10.4081/ripppo.2019.377

Soetanto, K., \& Zhou, Y. H. (2010, June). Notice of Retraction: Study on Freeter and NEET and its measure. In 2010 international conference on financial theory and engineering (pp. 267-270). IEEE.

Standing, G. (2014). Prekarya Yeni Tehlikeli Sınıf. Çev: Ergin Bulut, İstanbul: İletişim Yayınlar1.

Statista. (2021, 8 Nisan). Mean age at first marriage in Japan from 1955 to 2019, by gender. Erişim adresi: https://www.statista.com/statistics/611957/japan-mean-agemarriage-by-gender/\#: :text=According\%20to\%20a\%20statistic $\% 20$ about,when $\% 20$ they $\% 20$ first $\% 20$ got $\% 20$ married.

Statistics Bureau of Japan (2021a, 30 Mayıs). Unemployed person by age group. Erişim adresi: https://www.stat.go.jp/english/index.html

Statistics Bureau of Japan (2021b, 30 Mayıs). Elderly Population. Erişim adresi: https:// www.stat.go.jp/data/topics/topi1261.html

Stavropoulos, V., Anderson, E. E., Beard, C., Latifi, M. Q., Kuss, D., \& Griffiths, M. (2019). A preliminary cross-cultural study of Hikikomori and Internet Gaming Disorder: The moderating effects of game-playing time and living with parents. Addictive Behaviors Reports, 9, 1-10. https://doi.org/10.1016/j.abrep.2018.10.001

Stip, E., Thibault, A., Beauchamp-Chatel, A., \& Kisely, S. (2016). Internet addiction, hikikomori syndrome, and the prodromal phase of psychosis. Frontiers in psychiatry, 7 , 1-6. 10.3389/fpsyt.2016.00006

Suwa, M., \& Hara, K. (2007). Hikikomori'among Young Adults in Japan. Journal of medical welfare, 3, 94-101.

Suwa, M., \& Suzuki, K. (2013). The phenomenon of "hikikomori"(social withdrawal) and the socio-cultural situation in Japan today. Journal of Psychopathology, 19, 191-198.

Suzuki, M. A. (2020). Modern Hermits: Hikikomori (Doctoral dissertation, University of Oregon).

T.C Dışişleri Bakanlığı .(2021, 8 Nisan). Japonya'nın Ekonomisi. Erişim Adresi: https:// www.mfa.gov.tr/japonya_ekonomisi.tr.mfa

Tajan, N., Yukiko, H., \& Pionnié-Dax, N. (2017). Hikikomori: The Japanese Cabinet Office's 2016 survey of acute social withdrawal. The Asia Pacific Journal, 15(5), 1-11.

Tateno, M., Teo, A. R., Ukai, W., Kanazawa, J., Katsuki, R., Kubo, H., \& Kato, T. A. (2019). Internet addiction, smartphone addiction, and Hikikomori trait in Japanese young adult: social isolation and social network. Frontiers in psychiatry, 10, 1-11. https://doi.org/10.3389/fpsyt.2019.00455

Teo, A. R. (2013). Social isolation associated with depression: A case report of hikikomori. International Journal of Social Psychiatry, 59(4), 339-341. $10.1177 / 0020764012437128$ 
TÜİK. (2021a, 18 Mart). İstatisiklerle Yaşlılar, 2020. Erişim adresi: https://data.tuik.gov. tr/Bulten/Index?p=Elderly-Statistics-2020-37227

TÜİK. (2021b, 31 Mayıs). İgücü İstatistikleri. Erişim adresi: https://tuikweb.tuik.gov.tr/ PreTablo.do?alt_id=1007

TÜİK. (2021c, 31 Mayıs). Toplumsal Yapı ve Cinsiyet İstatistikleri. Erişim adresi: https:// tuikweb.tuik.gov.tr/PreTablo.do?alt_id=1068

Uchida, Y., \& Norasakkunkit, V. (2015). The NEET and Hikikomori spectrum: Assessing the risks and consequences of becoming culturally marginalized. Frontiers in psychology, 6, 1-11. https://doi.org/10.3389/fpsyg.2015.01117

Ueda, Y., \& Ohzono, Y. (2013). Comparison between freeters and regular employees: Moderating effects of skill evaluation on the age-satisfaction relationship. International Business Research, 6(5), 100-107. 10.5539/ibr.v6n5p100

Westelius, N. (2020). Twenty Years of Unconventional Monetary Policies: Lessons and Way Forward for the Bank of Japan. IMF Working Paper, WP/20/226, 1-27.

Wong, P. W., Li, T. M., Chan, M., Law, Y. W., Chau, M., Cheng, C., ... \& Yip, P. S. (2015). The prevalence and correlates of severe social withdrawal (hikikomori) in Hong Kong: A cross-sectional telephone-based survey study. International Journal of Social Psychiatry, 61(4), 330-342. 10.1177/0020764014543711

World Bank (2021a, 31 Mayıs). Population, total - Japan. Erişim adresi: https://data. worldbank.org/indicator/SP.POP.TOTL?locations=JP

World Bank (2021b, 31 Mayıs). GDP (current US\$) - Japan. Erişim adresi: https://data. worldbank.org/indicator/NY.GDP.MKTP.CD?locations=JP

World Bank (2021c, 31 Mayıs). Population ages 65 and above (\% of total population). Erişim adresi: https://data.worldbank.org/indicator/SP.POP.65UP.TO.ZS

Yamada, T. (2015). Investigating the function of social capital: a case study on selfhelp groups that have non-attendance school children. Hitotsubashi journal of social studies, 46(1), 1-17.

Yılmaz, Ö., \& Şahin, A. (2020). Japonya'da deflasyon döneminde işsizlik ve işsizlikle mücadele. Lectio Socialis, 4(1), 25-40.

Yılmaz, Y. (2021). Verimlilik Boyutuyla Yaşı İşgücü. F. Altun. (Ed.), Ekonomik ve Sosyal Boyutlarıyla Yaşlılık kitabı içinde ( s. 55-72). Ankara: Gazi Kitabevi.

Yong, R. K. F., \& Kaneko, Y. (2016). Hikikomori, a phenomenon of social withdrawal and isolation in young adults marked by an anomic response to coping difficulties: a qualitative study exploring individual experiences from first-and secondperson perspectives. Open Journal of Preventive Medicine, 6(01), 1-20. 10.4236/ ojpm.2016.61001

Yuen, J. W., Yan, Y. K., Wong, V. C., Tam, W. W., So, K. W., \& Chien, W. T. (2018). A physical health profile of youths living with a "Hikikomori" lifestyle. International journal of environmental research and public health, 15(2), 1-13. 10.3390/ ijerph15020315 
